Research Article

\title{
Challenges of impact assessment in Social Innovation: A qualitative study from two European rural regions
}

\section{Desafíos de la evaluación de impacto en la Innovación Social: Un estudio cualitativo de dos regiones rurales europeas}

\author{
Marina Novikova \\ ISCTE - Instituto Universitário de Lisboa, Lisbon, Portugal. \\ Correspondence: marina_novikova@iscte-iul.pt. Tel.: +351 210464031.
}

\begin{abstract}
Over recent years, various approaches to assessing the impacts of social innovation (SI) have developed without a uniform method having arisen. There are some issues around how impacts can be assessed, connected with the questions on the nature of impacts, the levels of analysis and effects of a purely positivist approach to impact assessment. While attempting to assess such impacts, various SI initiatives face the diversity of challenges. To this end, the aim of the article is to investigate the experience of said initiatives promoting social innovation related to impact assessment of social innovation. The paper is based on an empirical study conducted with the local development associations and local action groups involved in social innovation projects in two rural regions of Austria and Portugal. The results indicate that, despite recognising the importance of impact assessment regarding social innovation activities and the opportunities it provides, local organisations in question face many challenges in assessing the impacts of social innovation, including conceptual and practical difficulties.
\end{abstract}

Keywords: social innovation; impact assessment; rural regions; local development initiatives; Austria; Portugal.

Resumen: En los últimos años se han desarrollado diversos enfoques para evaluar los impactos de la innovación social (IS) sin que haya surgido un método uniforme. Existen algunas cuestiones en torno a la forma de evaluar los impactos, relacionadas con las preguntas sobre la naturaleza de los impactos, los niveles de análisis y los efectos de un enfoque puramente positivista de la evaluación de impactos. Al intentar evaluar dichos impactos, varias iniciativas de IS se enfrentan a la diversidad de desafíos. Para ello, el objetivo del artículo es investigar la experiencia de dichas iniciativas que promueven la innovación social en relación con la evaluación del impacto de la innovación social. El artículo se basa en un estudio empírico realizado con asociaciones de desarrollo local y grupos de acción local que participan en proyectos de innovación social en dos regiones rurales de Austria y Portugal. Los resultados indican que, a pesar de reconocer la importancia de la evaluación de impacto en relación con las actividades de innovación social y las oportunidades que ofrece, las organizaciones locales en cuestión se enfrentan a muchos retos a la hora de evaluar los impactos de la innovación social, incluyendo dificultades conceptuales y prácticas.

Palabras clave: innovación social; evaluación de impacto; regiones rurales; iniciativas de desarrollo local; Austria; Portugal. 


\section{Introduction}

Social innovation (SI) is growing in prominence in the fields of research, policy and practice. As a consequence, SI has been widely discussed and debated within various disciplines and traditions, leading to many different understandings of the SI nature. This has resulted in definitions and approaches that vary greatly. A number of studies has been done into SI, looking at the phenomenon from the perspective of urban studies and territorial development (MacCallum, 2009; Nyseth \& Hamdouch, 2019), rural studies (Bock, 2016; Neumeier, 2017), organisational studies (Tracey \& Stott, 2017), and business research (Van der Have \& Rubalcaba, 2016). Within all of the abovementioned fields, the questions surrounding the impacts of SI - and the ways in which such impacts can be evaluated, measured or assessed, - remain of utmost importance, since having an impact is said to be a cornerstone for any SI (Baturina \& Bezovan, 2015). However, such an array of diverse approaches to SI leads to the challenges of identifying SI and implementing assessments of SI impacts. Simultaneously, other challenges have been identified in previous research (Maas \& Liket, 2011; Grieco, 2015), including the difficulty of linking an objective value to impacts and summarising the various qualitative expressions of impacts (Liket \& Maas, 2015) and the contribution of many components to the impact while taking into account causality issue and the alternative attribution.

As such, the challenges that local development initiatives (LDIs) face go beyond the conceptual ambiguity of SI, and include other challenges that make the SI impact assessment a complicated task to carry out. The aim of this paper is, therefore, to present the results of the exploratory study discussing the challenges experienced by LDIs working on SI projects when it comes to the impact assessment of said SI interventions. In approaching this, the paper gives an overview of some key points from the field of impact assessment (IA) relevant to the current research, and then goes on to present the findings from empirical research examining the challenges that LDIs face concerning the impact assessment of their SI projects. By identifying SI as an action that a) is innovative with regard to the context or beneficiary, b) meets needs more effectively than previous actions/ projects/ initiatives, c) provides long-term solutions, and d) is adopted beyond the initial group/network that developed it (Neumeier, 2012, elaborated), the paper goes on to discuss the challenges of the local action groups (LAGs) and local development associations (LDAs), representing LDIs, with regards to the impact assessment. In the current paper, LDIs are considered to be important actors working in the field of SI in rural areas (Novikova, 2021). As such, the main contribution of the paper lies in providing the insights regarding challenges of impact assessment of SI projects, taking into account the rural context, hoping to further elaborate not only on the challenges, but also on the potential ways for improvement and some policy suggestions. As such, an attempt is made to suggest ways to address the challenges in a systematic manner and provide the directions for further discussion.

The paper is structured as follows. First, a brief overview of the state of the art in SI impact assessment will be presented. Second, the paper introduces the methodology of the current study. Following that, the main findings, discussing the challenges associated with assessing the SI impacts faced by local initiatives in two case studies, will be presented. Finally, some conclusions, alongside the limitations of the research and some policy recommendations, will be drawn.

\section{Theoretical framework}

\subsection{Social innovation: a brief introduction to the concept}

SI has been a concept on the rise over the last decades, both in academia and policy. Such attention to the concept and its core principles resulted in a myriad of understandings that revolve around new solutions in order to meet pressing needs that have not been met otherwise (Moulaert et. al., 2005), reconfiguration of social practices (Howaldt et al., 2016), changes in attitudes of local actors (Neumeier, 2012, 2017), as well as the ability of such innovation to 
challenge, alter and/or replace existing institutions and structures by recombining, transposing and reinventing specific elements (Avelino, 2021).

While there is no agreed definition of SI, there is a consensus that SI represents both "a process of the transformation of social practices (i.e., attitudes, behaviors, networks of collaboration) and the outcomes in terms of new products and services (i.e., novel ideas, models, services, and new organisational forms" (Ravazzoli et al., 2021: 2). As such, SI has been approached in a two-facet way that represents both the process and the outcomes achieved by such a change in the process and practices, with a particular focus recently being put on the transformative potential of SI. The transitions research (e.g Köhler et al., 2019) emphasises the potential of SI to contribute to the systemic change, seen as necessary in tackling 'wicked' (e.g., Nicholls et al., 2015) and 'persistent' (Schuitmaker, 2012) challenges modern societies are faced with. Being a motor of change (Bock, 2016), SI is also said to have a transformative potential (Avelino et al., 2019). Thus, transformative social innovation (TSI) is conceptualised as "social innovation that challenges, alters and/ or replaces existing social relations and practices, primarily by co-producing new social relations, involving new ways of doing, organising, framing and knowing" (Avelino et al., 2019: 198). Such an approach is echoed in the conceptualisation proposed by SIMRA where SI refers to "the reconfiguring of social practices, in response to societal challenges, which seeks to enhance outcomes on societal well-being and necessarily includes the engagement of civil society actors" (Ludvig et al., 2018: 147).

Consequently, SI is understood to represent "changes of attitude, behaviour and/or perception that result in new forms of collaborative action", which, then, improve the lives of those involved (Neumeier, 2012: 55). Thus, SI is not only about meeting unmet needs, it is also concerned with the way in which this is done (e.g., through enhancing the capacity of actors, building networks and empowering disadvantaged groups). It involves new forms of organisation at both an institutional and personal level, which are developed at the local level and result in social changes beneficial to the communities involved (Moulaert et al., 2005). As such, in view of Moulaert et al. $(2005,2013)$, SI (a) acst towards the satisfaction of human needs that are not currently satisfied; (b) provokes changes in governance to enable this satisfaction, and to increase the level of participation of all actors; and (c) fosters empowerment by enhancing socio-political capability and access to resources.

At the same time, the underlying importance of SI manifests due to a growing consensus among researchers, practitioners and policy makers that technological innovations alone are not capable of overcoming the challenges that modern societies are facing (Howaldt et al., 2018). Building upon the existing research, in the current paper SI is understood to trigger the reconfiguration of practices through changing, altering and/or replacing the previously existing practices with SI a) being innovative with regard to the context or beneficiary, b) meeting needs more effectively than previous actions/ projects/ initiatives, c) providing long-term solutions and d) being adopted beyond the initial group/network that developed it (Neumeier, 2012; Avelino et al., 2019).

\subsection{Social impacts and impact assessment in social innovation field}

The issue of impact is a cornerstone of the notion of SI, with some scholars arguing that having an impact is an inevitable part of the SI process, with an implicit emphasis on the SI impacts on individuals and society (Baturina \& Bezovan, 2015). Simultaneously, scholars argue that core elements of successful SI are durability and broad impact (Westley \& Antadze, 2010). Yet, one of the main challenges SI initiatives face is to show the impact it is having and how it is positively transforming society. Despite its relevance, the impact is an important issue addressed in the study of SI only to a certain extent (Portales, 2019).

With the research done on the topic of impact assessment, measurement and evaluation, one of the key questions in this area is still concerned with the notion of impact itself. In general, 
impact can be understood as the value created as a consequence of someone's activity and the value experienced by beneficiaries and all others affected (Kolodinsky et al., 2010). Simultaneously, (social) impact is understood as the change caused within a 'social system' (outcomes that result from outputs delivered by an intervention minus the change that would have happened anyway ('deadweight') (Clark et al., 2004; Ebrahim \& Rangan, 2014; Nicholls, 2009). Therefore, the impact represents the "effect at the final level of the causal chain that connects the action to the eventual impact on society" (Maas \& Grieco, 2017: 114). Such a causal chain, often referred to as impact value chain, makes a distinction between the initial resources used by the organisation to introduce an action (input); the action undertaken (project or activity); the immediate quantitative result of the action (output); the direct changes in the community, people, organisations, systems and institutions (outcome) followed by the highest order effects of the initial action undertaken (impact) (Ebrahim \& Rangan, 2014; Liket et al., 2014; Maas \& Grieco, 2017).

There is a growing understanding that accounting, measuring and reporting of the (social) impacts of organisations is important both for the organisations themselves and society at large (Mulgan, 2010; Epstein \& Yuthas, 2014; Arena et al., 2015; Nicholls, 2018). For the organisations, good social impact data holds an important added value in terms of informing and shaping strategy and operations; for the society, such data is vital as it supports legitimacy and marketing claims and "can be a key part of a sustainable resource strategy with key stakeholders" (Nicholls, 2018, p. 132). In broad terms, impact assessment describes a process in which an organisation itself or an external body develops and applies a methodology for capturing the measurable outcomes (impacts) of an organisation's specific activity or project from both a short and longterm perspective. Specifically, social impact assessment (SIA) is understood as "processes of analysing, monitoring and managing the intended and unintended social consequences, both positive and negative, of planned interventions (policies, programs, plans, projects) and any social change processes invoked by those interventions" (Vanclay, 2003:5).

Although the importance of (social) impact assessment has been pointed out by many scholars (e.g., Epstein \& Yuthas, 2014; Vanclay, 2020), one of the main obstacles when it comes to IA of SI is that both concepts of (social) impact and that of social innovation are understood differently depending on the field. Moreover, the existing approaches do not show a common understanding of what should be measured, why or for whom and how to measure it (Maas \& Liket, 2011). At the same time, conventional assessment and reporting approaches quite often fail to generate social impact data effectively (Ebrahim \& Rangan, 2010, 2014) or have been regarded as dysfunctional (Arya \& Mittendorf, 2015). Therefore, there is no common language, to date, on the impact assessment of SI activities and/or projects. Such IA faces several challenges such as causality issues where impacts cannot be attributed necessarily to a given activity, the intangible character of some impacts, the lack of available resources for the IA to be carried out at the level of the SI initiatives, and the lack of systematised data. At the same time, the nature of SI poses several challenges on the IA procedures. First, SI is always embedded into the context of a given community - with its relations, social capital and political environment, - which makes it sometimes difficult (or even hardly possible) to attribute the effects of such SI to the changes happening in the community. Second, being a dynamic process, SI takes place in ever-changing environments, thus needing to be changed and adapted to the wider context. Third, SI is a concept that has been adopted and used in many research fields and practices, which points to its crosscutting nature. Since SI does not represent only one specific field or sector, IA should be applied in a sensitive matter in order to take all those differences into account. Finally, since most of the time SI emerges within complex systems, the challenges - and the SI as a response to those challenges - are nonlinear and uncertain, which poses further difficulties in applying the IA to SI projects (European Commission, 2014).

However, with several attempts to suggest possible tools and frameworks for IA of SI (Antadze \& Westley, 2012; Nijnik et al., 2019; Ravazzoli et al., 2021), few studies addressed the 
challenges of the impact assessment of SI, providing a deeper understanding of the issue and analysing how such challenges affect the practices (and the possibility) of impact assessment of SI projects. As such, the current study takes a closer look at the specific experiences of the LDIs in two rural regions, with the methodology of the study presented in the following section.

\section{Methodology}

Current paper presents the results of an explorative study based on qualitative methodology. The data was collected between September 2018 and May 2019 in two rural regions, Baixo Alentejo in Portugal and Muehlviertel in Austria (Figure 1).

Two regions were selected as the areas under study due to their status as predominantly rural European regions (Eurostat, 2019), facing challenges such as outflow of the young population, aging population and lower or weakened economic activity. Such processes nominally correspond to the "circle of declining rural regions" (OECD, 2006) when regions experience low population density that leads to the lack of critical mass for infrastructure and services. In turn, fewer businesses are being created in those regions and fewer jobs are available for the younger population. This leads to the out - migration and aging population which feeds back into the 'circle of decline' (OECD, 2006). However, despite the perceived similarities, both Baixo Alentejo (PT) region and Muehlviertel (AT) region have undergone different rural development processes. Indeed, both regions under study have been regarded as rural regions; however, the two regions experience significant differences in recent developments that can be associated with their rural status. In recent decades, rural development has paid great attention to the necessity for the future development of rural regions looking beyond the challenges and turning such challenges into opportunities. Thus, the LDIs working in the field of SI have contributed to the development of their respective regions and have found their own approach to addressing existing challenges through SI, such as population decline, outflow of young people, lack of services, weakened economic performance, and overall rural marginalisation (Di Iacovo et al., 2014; Bock, 2016).

Figure 1. Map representing two regions under study.

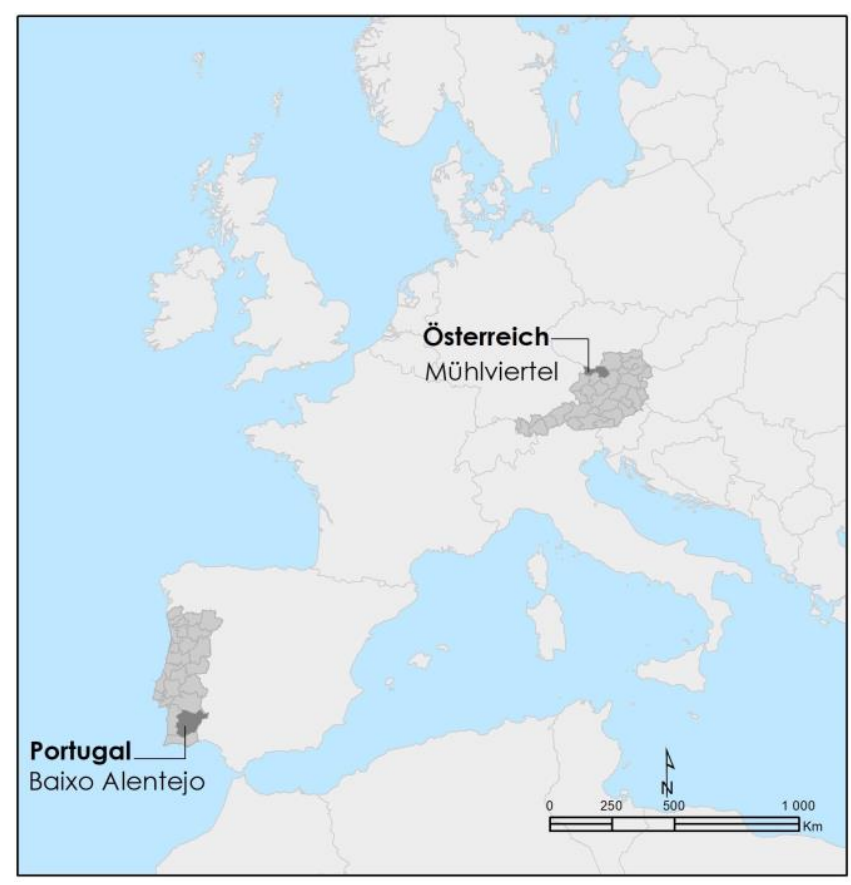

Source: Author's own elaboration based on Eurostat. 
The choice of two regions is also based on the fact that both territories represent case studies wherein a significant number of LDAs and LAGs pioneer in and contribute to local development and the promotion of SI (Novikova at al., 2020). In the current paper, LAGs and LDAs are understood to play an important role in developing, implementing and promoting bottom-up SI taking place in rural areas. As such, six LDAs corresponding to the Muehlviertel region and five LDAs corresponding to the Baixo Alentejo region were chosen since they exemplify a variety of initiatives in various fields of intervention such as sustainable agriculture, circular economy, community engagement, and capacity building, with the main aim of contributing to development of rural regions which they operate in.

Narrative data was collected through expert interviews. At the initial stage of the research, several groups of experts were identified. Following that, the sampling procedure was done through the snowballing technique (Noy, 2008), with key experts identified through the networks of other actors in the field. Despite the potential bias of such a technique that heavily relies on experts' personal connections and networks, this was done in an attempt to allow access to the specific groups with relevant experience in SI within local and regional settings. The groups contained representatives of actors from the local, regional, and national levels (see Table 1). In order to ensure the representation of many perspectives on the challenges associated with assessing the impacts of SI, some experts from the related fields were recruited for the interviews. Thus, together with the members and managers of LDAs and LAGs, policy makers, regional development experts, as well as project partners of the local initiatives took part in the research. This resulted in 15 interviews for Muehlviertel (AT) and 14 interviews for Baixo Alentejo (AT) regions, with a total of 29 interviews conducted.

Table 1. Number of interviews conducted with various experts.

\begin{tabular}{lcc}
\hline \multicolumn{1}{c}{ Group of experts } & Muehlviertel, AT & Baixo Alentejo, PT \\
\hline Managers and Staff of LAGs/ LDAs & 6 & 5 \\
\hline Policy Makers and External Experts & 3 & 2 \\
\hline Project Partners & 3 & 4 \\
\hline Extended Network & 3 & 3 \\
\hline Total & $\mathbf{1 5}$ & $\mathbf{1 4}$ \\
\hline
\end{tabular}

Source: Author's own elaboration.

The interview guide included open-ended questions that could be broken down into several categories. Alongside the questions focusing on a) the challenges two rural areas face (initial triggers), b) the responses provided by stakeholders aimed at solving those challenges through the projects, and c) the collaborative dimension of such work through exploring wider networks of actors involved in SI, a designated block was targeting the questions concerning the challenges in IA of SI. Such questions addressed the issues of i) (existing/ non-existing) practice of IA at the level of the SI initiative, ii) understanding of IA procedures, iii) challenges related to SI IA, including conceptual and practical challenges.

In order to comply with the ethical concerns of the research (e.g., Vanclay et al., 2013), informed consent was obtained for all interviews, elaborating both on the research procedures and the possibility for the interviewees to withdraw at any time. In both regions, the interviews 
were conducted either through the medium of English, or through the medium of the local language (German and Portuguese respectively).

Following the data collection, the interviews were transcribed and analysed using thematic analysis. As a method, thematic analysis helps in "identifying, analysing and reporting patterns (themes) within data" (Braun \& Clarke, 2006:79) constituted by several stages (ibid). The first stage includes generating of the initial codes which includes coding interesting features of the data in a systematic fashion across the entire data set. After the first stage of initial coding, the produced initial codes were used in order to identify emerging patterns and search for themes by collating codes into potential themes, gathering all data relevant to each potential theme. Following these steps, the process of reviewing themes was initiated where the themes were checked in relation to the coded extracts and the entire data set. As the themes that were identified as a result of coding were covering many domains, the current paper focuses on the various challenges the local development initiatives face associated with the impact assessment of their SI interventions.

Based on said analysis, the following section presents the results of the study, focusing on the challenges the actors of LDIs experience with assessing the impacts of the SI projects implemented in two regions under study.

\section{Challenges in capturing the impacts of social innovation projects}

LDIs in question face some crucial challenges when it comes to the impact assessment of the SI projects they implement, drawing the results based on the commonalities across both cases.

- Absence of a unified approach to SI impact assessment. In both research and practice, there is no agreement on what kind of indicators or metrics might capture the SI impacts or allow for the evaluation of SI to be carried out (Nicholls, 2015; Cunha \& Benneworth, 2020). Being cross-sectoral and multi-dimensional by its nature, SI impacts are difficult to measure since SI involves actors at a range of spatial scales, focusing on creating social value and community development (Baturina \& Bežovan, 2015), the dimensions that do not easily translate into the numerical forms. Such a quantitative-based approach to the impact assessment also puts at risk more intangible impacts (discussed later in more detail) where "what can be measured will be reported on" (Member of a local development association, May 2019), suggesting that the, on the one hand, not all the impacts have a numerical expression; on the other hand, those impacts that are difficult to attribute a numerical value to (or are not measurable), will end up not being reported on. Simultaneously, the complexity of impacts puts the possibility of such a universal SI IA under question.

The overall debate regarding whether there is a need - and, indeed, the possibility, - for one unified, universal assessment approach was discussed by the interviewees and regarded as one of the challenges they faced throughout the process of any assessment and/or evaluation of the impacts of their work. The fact that in the case of LAGs there are many variations in the way the indicators are being applied and that it leads to the confusion and even questioning of the need and purpose behind the whole assessment, was expressed by one of the experts:

$L A G$ creates its own indicators [...] for each action. And that means that its LAG has 15, 20, 30 indicators and 77 LAGs and each LAG has its own indicators. It means that the accumulation of indicators makes no sense. (Member of a LEADER forum, Austria, November 2018).

As such, the said absence of a unified approach to SI impact assessment is perceived as one of the most pressing challenges for LDIs wherein the actors find it difficult to navigate through the overwhelming diversity of approaches and identify (or design new and suitable) applicable tools that would capture the complexity of SI impacts. 
- Intangible character of the SI and its impacts. SI is understood in terms of new ideas, changes in attitudes, re-establishing practices and does not necessarily result in the development of a product (Krlev et al., 2014). It most often brings about an improvement in communities'well-being, altering and changing the existing practices, triggering more empowerment, eventually contributing to a more dynamic and productive society (BEPA, 2010). In addition to that, Phills et al. (2008) note that quite often SI produces something intangible, such as a principle, an idea, a piece of legislation, a social movement, or a civic intervention, rather than a tangible output (e.g., a product, process or technology). In the context of the rural studies, Neumeier (2012) echoes this idea, suggesting that SI is non-material, and any material outcome is a solely supplementary feature of it. Thus, the SI impacts are considered to be much more intangible than those of technical innovations, particularly those leading to the creation of new products or services. This helps explain the relative paucity of approaches measuring SI impact (Nicholls, 2015).

The question about the tangible and intangible character of the impacts was raised by the experts in both Muehlviertel and Baixo Alentejo. Interviewees describe the impacts of their work as being mostly 'intangible', long-term outcomes of the projects implemented. While describing the impacts as 'intangible', interviewees referred to the impacts that lead to a) the improved well-being of community members as a whole or some target groups, $b$ ) established and enhanced networking opportunities among and for the members of the community and c) the increased capacity of local communities, e.g., when it comes to starting their own initiatives and/ or enterprises. The supposed intangible nature of such impacts associated with the LDIs' actions imposes some restrictions on applying some of the existing assessment strategies, which frequently deal with measurable, clear outputs. Despite the fact that, for the said initiatives, such intangible impacts are difficult to assess, in both cases interviewees point out the importance of such 'quality work' being rooted in collaboration with local communities. Furthermore, they place a higher value as to the relevance of such interventions based on the opinion of local stakeholders, over tangible, measurable outputs. This indicates that factors such as an intervention's relevance to local stakeholders, the appreciation of action taken, and the public's perception (and satisfaction) opinion and personal assessments carry a significant weight in informal evaluation of the action taken than the results of the (formal) impact assessment procedures. As one of the interviewees puts it:

[The impact is] more than statistics can say. If you look at impact as the way people perceive the relevance of that intervention in their own lives, this is what matters to me and this I would very much like to know (Manager of a local development association, Baixo Alentejo, March 2019).

Both LAGs and LDAs in the two regions under study put greater emphasis on those impacts - as a consequence of their work - that enhance community cooperation, improve networking among members of a local community, and contribute to capacity building among the local population rather than the outputs that can be necessarily measured and presented in numerical form.

- Complex, non-linear nature of SI processes - and the issue of causality. SI is a change that comes about as a result of linkages between complex phenomena, social processes, and involves differentiated outcomes (Nicholls \& Dees, 2015). SI is not a static process, rather SI takes place within complex systems, while the wider transformative change is taking place (Wittmayer et al., 2019). Additionally, since most of the time SI emerges within complex systems, the dynamics of the challenges and the innovation are nonlinear, uncertain, and unpredictable (Goldstein et al., 2010; Westley \& Antadze, 2010) and the "cause-and-effect" means of IA are not 
easily applicable to SI projects (European Commission, 2014). As such, it is often hard to link activities and impact because of the causality issue as well as the alternative attribution mentioned previously. While discussing the impact assessment strategies and tools used by LDIs, the issue of causality and the link between the project implemented and the attribution of the impacts was brought up in both Baixo Alentejo and Muehlviertel regions. As put by a member of LDA from Portugal:

Even if you could realise that they were [connected], how could we really relate [it] to the project itself and not to any other factor that just happened during the same period? So [the impacts] it's always something very personal. (Member of a local development association, Portugal, March 2019).

The causal relationship between the action taken and impacts that have been observed cannot always be traced back to or attributed to a specific project implemented. In fact, the interviewees expressed the opinion that quite often other (contextual) factors have come into play where the importance of taking into account the context was explained through the high embeddedness of SI and its impacts. SI is advocated to emerge in a local, bottom-up process, where such initiatives are highly contextualised and respond to pressing needs of a specific group embedded in a specific territory. As such, any SI impact assessment has to account for a multitude of various (unique) features and factors corresponding to the needs specific to both community and territory, with SI processes being regarded as complex and socially embedded (Bund et al., 2015).

- Focus on output and outcome reporting. A common thread within the LDIs working in both regions is a strong shift towards output reporting rather than on impact assessment. This means that, at the end of each project or a broader time period, the initiatives prepare a report in which they present the outcome based evidence of the work done. Additionally, sometimes the impact assessment cannot be done by the local organisations because of specific time frames that do not allow for a longer post-evaluation over a period of time (e.g., 'projectification' of LDIs' work). While trying to implement the impact assessment strategies, the said initiatives face overall difficulties in delineating output and outcome reporting and the impact assessment. The main challenge here manifests itself when they have to go a step further after reporting on the outcomes and develop a set of impact indicators that will eventually be causally linked to the implementation of a project and its outputs and outcomes. One of the interviewees put it as follows:

Of course, we have both qualitative and quantitative results and present [them] in the end, in the final report. And those we can say that we achieved or not, but even being qualitative [results], there are not really impact indicators (Member of a local development association, Portugal, March 2019).

An important illustration of the difficulties regarding the delineation of outcome reporting and impact assessment was brought up by a LAG manager in the Baixo Alentejo region. While reflecting on impact assessment implementation, the interviewee said:

We do this [impact assessment]. One of the areas of this calculation is about the indicators of the employment created by enterprises. We report how many projects we supported, 10 projects, how many employees you got from this. We have all these in mind. Then we transform this in the reports and in this moment, we try to collect these results (LAG manager, Portugal, March 2019).

Supported by the above example, the LDIs find it challenging to trace the impacts rather than concentrating their reporting activities on outputs (e.g., number of participants in workshops) or outcomes (e.g., number of local enterprises started by 
the participants as a direct result of participating in an activity/ a workshop) of a project implemented.

- Practical challenges and bureaucratic burdens. The interviews revealed several other challenges related to the practical implementation and execution of IA. Firstly, the actors addressed the complexity of tools and methods of IA that exist in academia and practice. Having limited resources, actors both in Muehlviertel and Baixo Alentejo pointed out the need for additional training and support to actually engage in a meaningful assessment of the SI projects' impacts. Secondly, the actors pointed out the limited data availability on the SI projects, further leading to the challenges of ex-post evaluation. Such limited data availability is perceived as a great challenge since there is no structured way to gather the data needed for evaluation (Preskill \& Beer, 2012). Furthermore, one of the main challenges that was pointed out by the interviewees is the lack of necessary time required to execute such assessments. In addition to that, the LDIs are experiencing the lack of other resources needed to carry out IA. The issue of scarce resources is especially pressing since the members (and partners) of LDIs often lack the specialised knowledge and the know-how required to implement and carry out IA. This is in part due to lack of a suitably universal impact assessment of intangible impacts, which constitute a substantial portion of their work. Compounding this issue, quite often actors also find themselves caught between pressures coming from the monitoring bodies while at the same time being poorly supported in the process of impact assessment. Therefore, it is evident that the LAGs and LDAs find themselves in a situation where the impacts that they consider important are difficult to assess in a way that is strategically useful for them in terms of operation, finding funding etc. Last but not least, the interviews revealed insufficient culture for ex-post evaluation. Building upon the issue of the prevailing outcome reporting practices, one of the interviewees pointed out the constraints related to reporting on the impacts. As it was put,

We have to do it at the end of the project and there is no time, I think, at least from what I think of impact means, there is no time to really evaluate an impact, it cannot be something that you can evaluate a month after the project is .... When we apply, we usually have to propose results do not impact. (Member of a local development association, Portugal, March 2019).

As such, initiatives in question are quite often faced with the fact that the SI impact assessment requires a longer period of time to observe where the impacts manifest themselves later on - either throughout the project or upon assessing its impacts once the projects have been completed.

\section{Conclusions and discussion}

Current paper addressed some of the challenges faced by the LDIs in identifying the impacts of the SI projects run by those LDIs.

The results indicate that the organisations in question face some challenges when it comes to assessing impacts of the SI projects they implement. Firstly, one of the main challenges identified through the study was the absence of a unified approach to SI impact assessment with no agreement on what kind of indicators or metrics might capture the SI impacts or allow for the evaluation of SI to be carried out. Secondly, the results suggest that the impacts of SI projects of LDIs under study often take on an intangible character, with SI projects producing new principles, ideas, creating new social practices or changing attitudes within local communities towards cooperation, rather than producing a tangible output. Thirdly, the interviewees pointed out the challenges associated with attributing the impacts of an SI to a specific project and/or intervention due to the complexity and non-linearity of SI processes, as well as high embeddedness of SI in local context. Fourthly, the interviews revealed the intertwined character 
of outcome reporting and the impact assessment. Quite often, LDIs carry out what may be better understood as outcome reporting rather than impact assessment. This only partially concerns the long-lasting impacts of a given project where the impacts of the activities implemented by organisations are usually not documented over a period of time and, secondly, such impacts as there are difficult to attribute necessarily to any specific activity implemented (Maas \& Liket, 2011).

Additional challenges with the impact assessment come into play when it concerns the resource allocation for such activities. As to the main challenges concerning what resources are available for the impact assessment, the interviewees pointed out: 1) the lack of financial resources needed to support sustainable impact assessment procedures, 2) the lack of human resources required to keep the impact assessment last and 3) the lack of knowledge and expertise on how to develop and integrate the sustainable impact assessment culture into their work. As such, the combination of said factors makes the task of impact assessment rather difficult to carry out for the local development initiatives.

While having presented new insights into the challenges associated with impact assessment of SI among rural LDIs, current study has some limitations. First, a closer look into the assessment strategies of potential negative impacts of SI is required in order to gain a deeper understanding of how SI, while targeting and favouring some communities and/ or groups, can potentially create undesirable, sometimes even negative impacts. Second, an inclusion of other groups of stakeholders, such as monitoring bodies and external experts in IA, could benefit current research by providing a range of opinions regarding other challenges, as well as ways of addressing these challenges, driving forces and necessities behind the impact assessment of SI in rural regions.

Having discussed challenges of the SI impact assessment, the paper suggests some direction for the future research. Despite the fact that SI is often seen and discussed in light of its potential for a positive change, it can be misused. There have been several cautionary remarks about the potential for SI to contribute to the ever-growing trend of public withdrawal from social services (Ziegler, 2017; Grieco, 2015). As SI is often used as a policy design tool to find new means to fund and support alternatives to public services, there has been a growing number of authors questioning if SI is not furthering neoliberal interests. This side of SI - and, indeed, of innovation in general-is often overlooked, as the discourse on SI tends to stress the positive dimensions and hide the less desirable outputs (Epstein \& Yuthas, 2014) which has been called the pro-innovation bias of innovation (Goldstein et al., 2010). As such, further research is needed in the domain of the pro-innovation bias, and whether such bias is intertwined with the IA of SI.

Despite the impacts being approached by interviewees as indeed being present as a result of their work and as having a positive influence on the communities they work in; it should be noted that negative impacts were rarely spoken about in the context of SI. The absence of potential negative impacts vis-a-vis SI in the narratives and discourse around SI activities could be explained through an overly idealised perception of SI as a 'perfect solution' for the challenges that rural regions face. Since potential negative impacts were not in the scope of the study, it is important to address the issue in further research, and to explore the potential factors that may come into play when talking about, as well as assessing the negative impacts that could emerge.

Future research could also benefit from a stronger focus on the contextual factors of the environment LAGs and LDAs work in, alongside a more in-depth examination of the political and institutional frameworks under which those organisations operate. Such research could shed more light on the issues as to for what reasons and in what ways the organisations are expected to assess the impacts and report on them.

Resulting from the issues discussed above, several policy suggestions can be made in order to address the challenges of impact assessment for the organisations in question. Despite still being quite general, policy suggestions presented might give a sense of direction to both the policy makers and the practitioners in their endeavours concerning the SI impact assessment. Firstly, SI initiatives require more (extensive) knowledge on the existing and available tools for 
conducting impact assessments of their socially innovative projects. This can be achieved through partnering with peers (other LDIs and SI initiatives) and/or other partners (e.g., universities) that have more theoretical and practical skills in impact assessment. Secondly, the initiatives working in the field of SI could benefit from more exchanges of know-how and experiences with other organisations and expert bodies focusing on impact assessment procedures. The neo-endogenous approach comes into play when local actors are seeking support from extra-local bodies in the procedures of assessing and evaluating the impacts of the projects implemented (e.g., the support of intermunicipal communities, federations of local action groups). Thirdly, impact assessment requires extensive resources - both human and financial - that quite often are lacking at the organisational level. Therefore, more support infrastructure could be offered by the regional and national frameworks and institutions (such as Rural Development Program, LEADER contact points), to the SI initiatives in implementing and running impact assessments in a comprehensive way. Fourthly, the long-term character of SI impacts requires some time and perspective in order to be assessed and evaluated. One of the potential solutions arising from empirical research might be a task force allowing follow-up with the participants of the project to provide a platform to reflect on the potential impacts after finalising the projects. Lastly, as suggested, SI might have a "dark side", e.g., the potential negative impacts of innovation policy on society (Fougère \& Meriläinen, 2019), socially divisive or destructive objectives and intentions (Nicholls et al., 2015), as well as deviant or unintended consequences that achieve negative social effects (e.g., widened social exclusion as a result of some groups falling out of focus). Therefore, SI initiatives should strive for a more reflective impact assessment approach concerning the potential negative impacts produced as a result and/or as a by-product of the SI implemented.

\section{Acknowledgements}

This research has been carried out in the framework of the RurAction project that has received funding from the European Union's Horizon 2020 Research \& Innovation Programme under the Marie Sklodowska-Curie grant agreement No. 721999. The author would like to thank the interview partners for their collaboration, as well as the reviewers for their valuable and insightful feedback.

\section{References}

Antadze, N., \& Westley, F. R. (2012). Impact metrics for social innovation: Barriers or bridges to radical change? Journal of Social Entrepreneurship, 3(2), 133-150. https://doi.org/10.1080/19420676.2012.726005

Arena, M., Azzone, G., \& Bengo, I. (2015). Performance measurement for social enterprises. VOLUNTAS: International Journal of Voluntary and Nonprofit Organizations, 26(2), 649-672. https://www.jstor.org/stable/43654699

Arya, A., \& Mittendorf, B. (2015). Supply chain consequences of subsidies for corporate social responsibility. Production and Operations Management, 24(8), 1346-1357. https://doi.org/10.1111/poms.12326

Avelino, F., Wittmayer, J. M., Pel, B., Weaver, P., Dumitru, A., Haxeltine, A., ... \& O'Riordan, T. (2019). Transformative social innovation and (dis) empowerment. Technological Forecasting and Social Change, 145, 195-206. https://doi.org/10.1016/j.techfore.2017.05.002

Avelino, F. (2021). Theories of power and social change. Power contestations and their implications for research on social change and innovation. Journal of Political Power, 1-24. https://doi.org/10.1080/2158379X.2021.1875307 
Baturina, D., \& Bežovan, G. (2015). Social innovation impact-review. Seventh Framework Programme, Third Sector Impact. Brussels.

BEPA. (2010). Empowering People, Driving Change. Social Innovation in the European Union. Bureau of European Policy Advisers and European Commission.

Bock, B. B. (2016). Rural marginalisation and the role of social innovation; a turn towards nexogenous development and rural reconnection. Sociologia Ruralis, 56(4), 552-573. https://doi.org/10.1111/soru.12119

Braun, V., \& Clarke, V. (2006). Using thematic analysis in psychology. Qualitative research in psychology, 3(2), 77-101.

Bund, E., Gerhard, U., Hoelscher, M., \& Mildenberger, G. (2015). A methodological framework for measuring social innovation. Historical Social Research/Historische Sozialforschung, 48-78.

Burdge, R. J., \& Vanclay, F. (1996). Social impact assessment: a contribution to the state of the art series. Impact Assessment, 14(1), 59-86. https://doi.org/10.1080/07349165.1996.9725886

Chatzichristos, G., \& Nagopoulos, N. (2020). Regional Institutional Arenas for Social Innovation: mixed methods research. Journal of Social Entrepreneurship, 1-23. https://doi.org/10.1080/19420676.2019.1705378

Clark, C., Rosenzweig, W., Long, D., \& Olsen, S. (2004). Double Bottom Line Project Report: Assessing Social Impact in Double Line Ventures. New York. Available online at: http://citeseerx.ist.psu.edu/viewdoc/download?doi=10.1.1.516.916\&rep=rep1\&type=pdf $\quad$ (accessed 21 November).

Cunha, J., \& Benneworth, P. (2020). How to measure the impact of social innovation initiatives? International Review on Public and Nonprofit Marketing, 17(1), 59-75. https://doi.org/10.1007/s12208-019-00240-4

Di Iacovo, F., Moruzzo, R., Rossignoli, C., \& Scarpellini, P. (2014). Transition management and social innovation in rural areas: Lessons from social farming. The Journal of Agricultural Education and Extension, 20(3), 327-347. https://doi.org/10.1080/1389224X.2014.887761

Ebrahim, A., \& Rangan, V. K. (2010). The limits of nonprofit impact: A contingency framework for measuring social performance (No. 10-099). Harvard Business School.

Ebrahim, A., \& Rangan, V. K. (2014). What impact? A framework for measuring the scale and scope of social performance. California management review, 56(3), 118-141. https://doi.org/10.1525/cmr.2014.56.3.118

Epstein, M.J., \& Yuthas, K. (2014). Measuring and improving social impacts: A guide for nonprofits, companies, and impact investors. Berrett-Koehler Publishers. Available online: https://www.bkconnection.com/static/Measuring_and_Improving_Social_Impacts_EXCERPT.pdf (accessed 23 April 2021).

European Commission. (2014). Proposed approaches to social impact measurement in European Commission legislation and in practice relating to EUSEFs and the EaSI: GECES sub-group on impact measurement. European Commission Publications Office. https://data.europa.eu/doi/10.2767/29691

Eurostat. (2019). Available online: https://ec.europa.eu/eurostat/statisticsexplained/index.php/Archive:Rural_development_statistics_by_urban-rural_typology （accessed 12 December 2019).

Fougère, M., \& Meriläinen, E. (2021). Exposing three dark sides of social innovation through critical perspectives on resilience. Industry and Innovation, 28(1), 1-18. https://doi.org/10.1080/13662716.2019.1709420

Goldstein, J., Hazy, J. K., \& Silberstang, J. (2010). A complexity science model of social innovation in social enterprise. Journal of social entrepreneurship, 1(1), 101-125. https://doi.org/10.1080/19420671003629763 
Grieco, C. (2015). Assessing social impact of social enterprises: Does one size really fit all? Springer.

Howaldt, J., Domanski, D., \& Kaletka, C. (2016). Social innovation: Towards a new innovation paradigm. RAM. Revista de Administração Mackenzie, 17(6), 20-44. https://doi.org/10.1590/167869712016/administracao.v17n6p20-44

Howaldt, J., Kaletka, C., Schröder, A., \& Zimgiebl, M. (Eds.). (2018). Atlas of social innovation: new practices for a better future. Technische Universität Dortmund, ZWE Sozialforschungsstelle.

Köhler, J., Geels, F. W., Kern, F., Markard, J., Onsongo, E., Wieczorek, A., ... \& Wells, P. (2019). An agenda for sustainability transitions research: State of the art and future directions. Environmental innovation and societal transitions, 31, 1-32. https://doi.org/10.1016/j.eist.2019.01.004

Kolodinsky, R. W., Madden, T. M., Zisk, D. S., \& Henkel, E. T. (2010). Attitudes about corporate social responsibility: Business student predictors. Journal of Business Ethics, 91(2), 167-181. https://doi.org/10.1007/s10551-009-0075-3

Krlev, G., Bund, E., \& Mildenberger, G. (2014). Measuring what matters - Indicators of social innovativeness on the national level. Information Systems Management, 31(3), 200-224. https://doi.org/10.1080/10580530.2014.923265

Liket, K. C., \& Maas, K. (2015). Nonprofit organizational effectiveness: Analysis of best practices. Nonprofit and Voluntary Sector Quarterly, 44(2), 268-296. https://doi.org/10.1177/0899764013510064

Liket, K. C., Rey-Garcia, M., \& Maas, K. E. (2014). Why aren't evaluations working and what to do about it: A framework for negotiating meaningful evaluation in nonprofits. American Journal of Evaluation, 35(2), 171188. https://doi.org/10.1177/1098214013517736

Ludvig, A., Weiss, G., Sarkki, S., Nijnik, M., \& Živojinović, I. (2018). Mapping European and forest related policies supporting social innovation for rural settings. Forest Policy and Economics, 97, 146-152. https://doi.org/10.1016/j.forpol.2018.09.015

Maas, K., \& Grieco, C. (2017). Distinguishing game changers from boastful charlatans: Which social enterprises measure their impact? Journal of Social Entrepreneurship, 8(1), 110-128. https://doi.org/10.1080/19420676.2017.1304435

Maas, K., \& Liket, K. (2011). Social impact measurement: Classification of methods. In R. Burritt, S. Schaltegger, M. Bennett, T. Pohjola \& M. Csutora (Eds.), Environmental management accounting and supply chain management (pp. 171-202). Springer.

MacCallum, D. (2009). Social innovation and territorial development. Ashgate Publishing.

Moulaert, F., Martinelli, F., Swyngedouw, E., \& Gonzalez, S. (2005). Towards alternative model (s) of local innovation. Urban studies, 42(11), 1969-1990. https://doi.org/10.1080/00420980500279893

Moulaert, F. (2013). The international handbook on social innovation: collective action, social learning and transdisciplinary research. Edward Elgar Publishing.

Mulgan, G. (2010). Measuring social value. Stanford Social Innovation Review, 8(3), 38-43.

Neumeier, S. (2012). Why do social innovations in rural development matter and should they be considered more seriously in rural development research? -Proposal for a stronger focus on social innovations in rural development research. Sociologia Ruralis, 52(1), 48-69. https://doi.org/10.1111/j.1467-9523.2011.00553.x

Neumeier, S. (2017). Social innovation in rural development: identifying the key factors of success. The geographical journal, 183(1), 34-46. https://doi.org/10.1111/geoj.12180 
Nicholls, A., Simon, J., \& Gabriel, M. (2015). Introduction: Dimensions of social innovation. In A. Nicholls, J. Simon \& M. Gabriel (Eds.), New frontiers in social innovation research (pp. 1-26). Palgrave Macmillan.

Niccholls, A. (2015). Synthetic grid: a critical framework to inform the development of social innovation metrics. CRESSI Working papers, 14. Oxford, Creating Economic Space for Social Innovation (CRESSI) project.

Nicholls, A. (2018). A general theory of social impact accounting: Materiality, uncertainty and empowerment. Journal of Social Entrepreneurship, 9(2), 132-153.

Nicholls, A., \& Dees, J.G. (2015). Social Innovation. In J. D. Wright (Ed.), International Encyclopedia of the Social $\mathcal{E}$ Behavioral Sciences (pp. 355-361). Elsevier.

Nijnik, M., Secco, L., Miller, D., \& Melnykovych, M. (2019). Can social innovation make a difference to forestdependent communities? Forest Policy and Economics, 100, 207-213. https://doi.org/10.1016/j.forpol.2019.01.001

Novikova, M., de Fátima Ferreiro, M., \& Stryjakiewicz, T. (2020). Local Development Initiatives as Promoters of Social Innovation: Evidence from Two European Rural Regions. Quaestiones Geographicae, 39(2), 43-53. https://doi.org/10.2478/quageo-2020-0012

Novikova, M. (2021). Transformative Social Innovation in Rural Areas: Insights from a Rural Development Initiative in the Portuguese Region of Baixo Alentejo. European Countryside, 13(1), 71-90. https://doi.org/10.2478/euco-2021-0005

Noy, C. (2008). Sampling knowledge: The hermeneutics of snowball sampling in qualitative research. International Journal of social research methodology, 11(4), 327-344. https://doi.org/10.1080/13645570701401305

Nyseth, T., \& Hamdouch, A. (2019). The transformative power of social innovation in urban planning and local development. Urban Planning, 4(1), 1-6. https://doi.org/10.17645/up.v4i1.1950

Organisation for Economic Cooperation and Development. (2006). The new rural paradigm: Policies and governance. OECD Publishing.

Phills, J. A., Deiglmeier, K., \& Miller, D. T. (2008). Rediscovering social innovation. Stanford Social Innovation Review, 6(4), 34-43.

Preskill, H., \& Beer, T. (2012). Evaluating social innovation. Available online: https://repository.fteval.at/146/1/2012_Evaluating\%20Social\%20Innovation.pdf (assessed 11 June 2021).

Ravazzoli, E., Dalla Torre, C., Da Re, R., Marini Govigli, V., Secco, L., Górriz-Mifsud, E., ... \& Nijnik, M. (2021). Can social innovation make a change in European and Mediterranean marginalized areas? Social innovation impact assessment in agriculture, fisheries, forestry, and rural development. Sustainability, 13(4), 1823. https://doi.org/10.3390/su13041823

Schuitmaker, T. J. (2012). Identifying and unravelling persistent problems. Technological Forecasting and Social Change, 79(6), 1021-1031. https://doi.org/10.1016/j.techfore.2011.11.008

Tracey, P., \& Stott, N. (2017). Social innovation: a window on alternative ways of organizing and innovating. Innovation, 19(1), 51-60. https://doi.org/10.1080/14479338.2016.1268924

Vanclay, F., Baines, J. T., \& Taylor, C. N. (2013). Principles for ethical research involving humans: ethical professional practice in impact assessment Part I. Impact assessment and project appraisal, 31(4), $243-253$. https://doi.org/10.1080/14615517.2013.850307

Vanclay, F. (2003). International principles for social impact assessment. Impact assessment and project appraisal, 21(1), 5-12. https://doi.org/10.3152/147154603781766491 
Vanclay, F. (2020). Reflections on Social Impact Assessment in the 21st century. Impact Assessment and Project Appraisal, 38(2), 126-131. https://doi.org/10.1080/14615517.2019.1685807

Van der Have, R.P. and Rubalcaba, L., 2016. Social innovation research: An emerging area of innovation studies? Research Policy, 45(9), 1923-1935. https://doi.org/10.1016/j.respol.2016.06.010

Westley, F., \& Antadze, N. (2010). Making a difference: Strategies for scaling social innovation for greater impact. Innovation Journal, 15(2), 1-19.

Wittmayer, J. M., Backhaus, J., Avelino, F., Pel, B., Strasser, T., Kunze, I., \& Zuijderwijk, L. (2019). Narratives of change: How social innovation initiatives construct societal transformation. Futures, 112, 102433. https://doi.org/10.1016/j.futures.2019.06.005

Ziegler, R. (2017). Social innovation as a collaborative concept. Innovation: The European Journal of Social Science Research, 30(4), 388-405. https://doi.org/10.1080/13511610.2017.1348935

\section{@) $\mathbb{Q} \Theta \Theta$}

(C) Attribution-NonCommercial-NoDerivatives 4.0 International (CC BY-NC-ND 4.0)

https://creativecommons.org/licenses/by-nc-nd/4.0/ 